\title{
RETINAL GANGLION CELL TERMINALS CHANGE THEIR PROJECTION SITES DURING LARVAL DEVELOPMENT OF RANA PIPIENS ${ }^{1}$
}

\author{
THOMAS A. $\mathrm{REH}^{2}$ AND MARTHA CONSTANTINE-PATON
}

Department of Biology, Princeton University, Princeton, New Jersey 08544

Received April 25, 1983; Revised August 8, 1983; Accepted August 25, 1983

\begin{abstract}
Interconnecting neuronal populations in the vertebrate CNS are typically not well matched in their overall topographic patterns of histogenesis and differentiation during development. One striking example of this mismatch is the retinotectal system of the frog, where the retina grows in concentric annuli, while the optic tectum, a major retinal target, adds new neurons at only the caudo-medial border. The retinal ganglion cell (RGC) terminals nevertheless form an organized map in the tectum during the period when the two structures are undergoing such disparate modes of growth. This led Gaze et al. (Gaze, R. M., M. J. Keating, and S. H. Chung (1974) Proc. R. Soc. Lond. (Biol.) 185: 301-330) to propose that the terminals must shift caudally during development. In the present study, we have directly tested the hypothesis of "shifting connections" by selectively labeling an identified population of RGC terminals, those at the optic nerve head (ONH), and determining their tectal projection site relative to a particular group of $\left[{ }^{3} \mathrm{H}\right]$ thymidine-labeled tectal neurons. With this double-label technique, we have found that RGC terminals from cells at the $\mathrm{ONH}$ move from a position rostral to the $\left[{ }^{3} \mathrm{H}\right]$ thymidine-labeled tectal cells to a position caudal to these same cells during the latter half of larval development. This represents a movement of approximately $1.4 \mathrm{~mm}$ across the tectal surface between stages T\&K XII and T\&K XXV. In addition, we have used electron microscopy and electrophysiology to demonstrate that the RGC terminals make functional synaptic connections during this period. This indicates that RGC terminals continually change the tectal neurons with which they form functional synapses during the development of the retinotectal system. We propose that such moving, but highly ordered connections can best be explained by a two stage mechanism for map formation, in which graded selective adhesions between cells in appropriate regions of retina and tectum provide the overall gross retinotopy of the projection, while competitive interactions between RGC terminals are responsible for the refinement of the precision in this system.
\end{abstract}

In recent years, increasing evidence has indicated that mature, highly stereotyped neuronal connections are not rigidly dictated. For example, a wide variety of manipulations performed on either developing or regenerating neural pathways can result in the formation of anomalous connections (for review see Lund, 1978; Tsukahara, 1981). This plasticity in experimental preparations is underscored by studies of normal vertebrate development that demonstrate the presence of transient axonal projections and termination patterns (Rakic, 1976; Hubel et

\footnotetext{
${ }^{1}$ We acknowledge the technical assistance of $P$. Ferrari-Eastman and J. Piotrowski and thank J. Nielsen for typing the manuscript. The work was supported by National Institutes of Health Grant EY0537901 to T. A. R., National Science Foundation Grant BNS-8110225, and National Institutes of Health Grant EY01872-06.

${ }^{2}$ To whom correspondence should be addressed.
}

al., 1977; Springer, 1980; Innocenti, 1981). Thus, in many systems initial synaptic contacts may be formed in a less precise way, only to be later refined by collateral withdrawal, cell death, or synaptic rearrangement. Such a multi-stage process may well be necessary during development to ensure a best fit of two interconnecting neural structures that are not well matched in their spatial or temporal patterns of cell proliferation.

The retinotectal projection represents one striking example of this type of qualitative mismatch in the overall growth patterns of connecting neuronal populations. In the vertebrates that have been studied the retina has gradients of cell proliferation and differentiation that proceed roughly in a central to peripheral direction (Hollyfield, 1968, 1972; Braekevelt and Hollenberg, 1970; Rager, 1980; Rapaport and Stone, 1982; Reh and Constantine-Paton, 1983). However, in frogs (Straznicky and 
Gaze, 1972; Currie and Cowan, 1974), chickens (LaVail and Cowan, 1971), and rodents (Altman and Bayer, 1981) the tectal lobes or superior colliculi of the midbrain have a gradient of cell proliferation and maturation that proceeds from rostrolateral to caudomedial.

The incongruity of growth between the retina and its tectal target was first identified by Gaze et al. (1974) in the clawed frog, Xenopus. Since the retina projects to the tectum in an organized visuotopic map while the two structures are still adding new cells, Gaze hypothesized that the developing retinal projection must continually shift from rostral tectal positions to successively more caudal positions as the tectum matures in order to accommodate the disparate patterns of growth. However, this proposal has engendered controversy, since other studies have demonstrated that in Xenopus the patterns of growth of the retina and tectum become closely matched at certain stages of development (Beach and Jacobson, 1979). Furthermore, no direct test of the hypothesis has yet demonstrated that a particular group of retinal ganglion cell (RGC) terminals makes functioning synaptic connections with tectal cells in postmetamorphic frogs different from those contacted in the larval animal. In this study we take advantage of the distinctly incongruous patterns of retinal and tectal growth exhibited by the frog, Rana pipiens, and we use anterograde transport of horseradish peroxidase combined with $\left[{ }^{3} \mathrm{H}\right]$ thymidine autoradiography to directly test the hypothesis of shifting retinotectal synapses.

\section{Materials and Methods}

Laboratory-raised northern leopard frogs and tadpoles (Rana pipiens) were used in this study. Adult breeders (J. M. Hazen \& Co., Alburg, VT) were induced to ovulate, and the eggs were artificially fertilized. The results reported in this study are from animals of three separate rearing batches over the period of 1 year. To ensure controlled growth conditions, the tadpoles were maintained in 3- to 5 -liter tubs in a $23^{\circ} \mathrm{C} \pm 1^{\circ} \mathrm{C}$ temperaturecontrolled incubator with a 12 -hr light, 12 -hr dark regimen. Embryonic animals were kept in 20\% Steinberg's solution and larvae were raised in $12 \%$ Steinberg's solution diluted 1:1 with charcoal-filtered water. Tadpoles were fed powdered nettle and boiled lettuce. The animals were staged by the system of Taylor and Kollros (1946; T\&K). For all surgical procedures the animals were anesthetized by topical application of $0.05 \%$ methanesulfonic acid (MS-222, Sigma Chemical Co., St. Louis, MO).

Optic nerve head projection position. The tectal projection site of RGCs immediately surrounding the optic nerve head $(\mathrm{ONH})$ was visualized in animals of several larval stages and in postmetamorphic frogs by one of two methods. In the first method, the entire retina was removed except for that part adjacent to the optic nerve. The orbit was then packed with pellets of solid, recrystallized horseradish peroxidase (HRP; Boehringer Mannheim Grade I) and sealed with cyanoacrylic tissue glue (Histoacryl, Tri Hawk Int., Montreal). After a 1- to 2-day survival period, the unsectioned and unfixed brain was reacted with diaminobenzidine tetrahydrochloride (DAB; Sigma Grade II) using a whole mount procedure adapted from Fujisawa et al. (1981), as described in Reh et al. (1983). With this method, only those axons that had been cut by the surgery - those from more peripheral RGCs-transported the HRP. Those axons from the most central RGCs were not cut and therefore did not take up and transport the label. The result of this procedure is a negative image of the $\mathrm{ONH}$ position. The projection of the $\mathrm{ONH}$ appears as an unlabeled spot while the rest of the retinotectal projection contains the dark brown DAB reaction product (Fig. $2 a$ ).

The second method of visualizing the tectal projection site of ganglion cells at the ONH grew out of previous observations concerning the organization of the optic pathway in $R$. pipiens. As also reported for fish (Easter et al., 1981), RGC axons are bundled in an age-related fashion during part of their course in the optic pathway of $R$. pipiens. In Rana, axons first coalesce into the discrete age-related bundles at the optic chiasm and they remain bundled in this way through the rest of their course to the optic tectum (Reh et al., 1983). These bundles of fibers can be selectively labeled by making small HRP injections into either the optic chiasm or the optic tract. The enzyme is inserted as a small recrystallized pellet of HRP that has been dried onto the tip of a fine insect pin. When the brains of these animals are reacted as whole mounts following a 1- to 2-day survival, striking annular patterns of terminals are labeled in the tectal lobes (Constantine-Paton et al., 1983; Reh et al., 1983). Similarly, when the retinas of the same animals are flat mounted onto slides and reacted with $\mathrm{DAB}$, rings of ganglion cell bodies are labeled at radial positions that correspond to those of the terminals (Fig. 1). With this method, we were often able to label small annuli of terminals in the tectal lobe and corresponding annuli of ganglion cell bodies in central retina, adjacent to the ONH. Such small central annuli, therefore, reliably mark the tectal position of the axons of the most central (and hence oldest) RGCs.

Although we have been able to mark the tectal projection site of animals as early as T\&K VI, the results reported in this study concentrate on the following three stages: T\&K XII, XVIII, and XXV (postmetamorphic frog). The first method was used in 3 animals at each of these three stages, while the second method labeled small terminal annuli in 12 animals at T\&K XII, 7 animals at T\&K XVIII, and 6 animals at T\&K XXV. When the position of the projection site of the $\mathrm{ONH}$ was measured in its rostral-caudal extent (see below) there was no significant difference in the position as determined by the two methods. In addition no significant difference was found between the two tecta of the same animal. In the best cases, the first method allowed the visualization of the $\mathrm{ONH}$ projection to the tectum to within $200 \mu \mathrm{m}$, while the second method was accurate to within the diameter of the central terminal circle or $\operatorname{dot}(100 \mu \mathrm{m})$.

After the position of the terminals from the cells at the $\mathrm{ONH}$ was established by one of the above methods, the position of this point from the rostral tectal border was determined. Since the tectal surface is highly curved, we decided to measure this length on the whole mounted brains. To make these measurements, the total tectal length at a given stage was determined by stretching a small cotton fiber across the tectal surface between the rostral and caudal tectal poles. The rostral tectal pole 
was defined as the point on the rostral tectal border where the medial and lateral optic tracts diverge-i.e., midway between the dorsal and ventral limits of the tract, as it enters the mesencephalon. The caudal tectal pole was defined as the most caudomedial point at which the two tectal lobes are joined. The line thereby established along the rostrocaudal tectal axis closely approximates the line which divides the terminal arbors of axons from the medial optic tract from those contributed via the lateral tract (Constantine-Paton et al., 1983; see Reh et al., 1983). The cotton fiber stretched along this axis was then cut at the rostral and caudal points, mounted on a glass slide, and projected via a compound microscope drawing tube onto a digitizing bit pad. The length spanned by the fiber could then be reliably measured using a planimeter program and a Terak computer. For each tectum three fibers were measured and the average was recorded. Next, the distance between the tectal projection of the $\mathrm{ONH}$ and the rostral tectal border was measured along the same rostrocaudal line as was used for the total tectal length measures, and again the average length of three fibers per tectum was recorded.

$\left.{ }^{3} H\right]$ Thymidine labeling. In several animals, we used a double-labeling procedure to demonstrate that the tectal site of projection of ganglion cells at the $\mathrm{ONH}$ shifts caudally with respect to stable, identified tectal cells. Therefore, in these animals a small subset of tectal cells, born at a particular larval stage, were permanently labeled with systemic injections of $\left[{ }^{3} \mathrm{H}\right]$ thymidinc. Preliminary experiments in our laboratory, as well as the results of others (Currie and Cowan, 1974; Currie, 1975), had established that an injection of $\left[{ }^{3} \mathrm{H}\right]$ thymidine in a tadpole results in the labeling of a band of tectal cells, roughly in register throughout all tectal layers, that extends across the mediolateral axis of the tectum when the animal is fixed at a later stage. Moreover, when such injections are made at larval stage T\&K IV, the mediolateral band of labeled cells is approximately at the center of the rostrocaudal extent of the tectum. Therefore, several animals received 1 - to $3-\mu$ l injections of $1 \mu \mathrm{Ci}$ / $\mu$ mol of $\left[{ }^{3} \mathrm{H}\right]$ thymidine at T\&K IV (New England Nuclear, Boston, MA; $60 \mathrm{Ci} / \mathrm{mmol}$ ). These animals were allowed to survive until T\&K XII, T\&K XVIII, or T\&K $\mathrm{XXV}$, at which time the $\mathrm{ONH}$ projection position was mapped by the procedures described above. Then the brains were dehydrated, embedded in paraffin, sectioned at $10 \mu \mathrm{m}$ in the transverse plane, and processed for autoradiography. The positions of $\left[{ }^{3} \mathrm{H}\right]$ thymidine-labeled cells in layer 6 of every second section through the tectum were charted using the camera lucida-computer interface described above. Regardless of its depth in layer 6, each cell's position was projected to a point along the line representing the surface of layer 6 . A reconstruction program for the Terak aligned the midpoint of each charted section and plotted them to give a flattened representation of the tectal surface and the labeled band of cells (Fig. 5). In many animals the DAB reaction product of whole mounted brains did not penetrate the full depth of layer 9 and the position of the $\mathrm{ONH}$ projection site could not be reliably determined when the brains were sectioned for autoradiography. Therefore, prior to sectioning, a small shaft of hair was inserted through the tectal lobe at the center of the circle demarcating the projection of the $\mathrm{ONH}$. When the brain was subsequently sectioned the hair could be easily located (see Fig. 5) and charted on the tectal reconstructions. Depending on its orientation the hair could be observed in several adjacent 10- $\mu \mathrm{m}$ sections; the point labeled on the reconstructions represents the section at which the hair penetrated layer 6. This double-labeling technique was successfully carried out in the optic tecta from two animals at each of the three stages (XII, XVIII, XXV) mentioned above.

Electron microscopy. Four tadpoles (two at T\&K XVIII and two at T\&K XII) were processed for electron microscopy after receiving small HRP injections in the optic tract, to determine whether RGCs were making synapses in the tectum. One to 2 days after the HRP injection, the animals were prepared as whole mounts to verify that a central terminal annulus was labeled. The brains were then fixed for $12 \mathrm{hr}$ in phosphate-buffered $1 \%$ paraformaldehyde, $2 \%$ gluteraldehyde solution. They were then sectioned at $100 \mu \mathrm{m}$ on a Vibratome (Oxford Instruments, Inc., Columbia, MD) and re-reacted with $\mathrm{DAB}$ as sections to ensure adequate penetration of the reaction product throughout the entire depth of the tectal neuropil. Next, the sections containing the labeled terminal annulus were dehydrated in a graded series of alcohols and embedded between plastic slides in Durcupan (Polysciences Inc., Warrington, PA) resin. After the Durcupan was hardened, the $100-\mu \mathrm{m}$ sections were mounted on Epon/Araldite blocks, and thin sections were cut for study on a JEOL 100 LS electron microscope. Although the process of whole mounting the tecta prior to sectioning allowed verification that a central annulus had been labeled, the brains could not be fixed until the reaction was complete. Although labeled axons and terminals could be readily identified in this material, better ultrastructural preservation was obtained by fixing the brains by immersion in the primary fixative prior to Vibratome sectioning and reaction with DAB. Therefore, four additional tadpoles (two at T\&K XVIII and two at $T \& K$ XII) were processed in this manner.

Perfused brain preparation for electrophysiological experiments. Tadpoles of stages T\&K XII to XVIII and recent postmetamorphic frogs were prepared for electrophysiological recording by two methods. In the first method, postmetamorphic frogs were anesthetized with topical application of MS-222 and the tecta were exposed. They were then mounted in a stable position, and the pigmented dural membrane was removed. The animals were then paralyzed with succinylcholine $(0.5 \mathrm{mg} /$ $\mathrm{kg}$ ) and a small amount of local anesthetic was applied to the surgical wound surfaces. Tadpoles were prepared for recording in this same manner; however, since larval animals cannot exchange oxygen through their skin with the same efficiency as postmetamorphic animals, we found it necessary to continuously perfuse their gills with oxygenated water.

In the second method, tadpoles and recent postmetamorphic frogs were recorded from as perfused CNS preparations. For these recordings, animals were anesthetized with MS-222, and the heart was exposed. A small incision was made in the ventricle and a fine cannula was inserted through the ventricle and into the conus arteriosus. The 
cannula was cemented into place with cyanoacrylic glue and the major cerebral sinuses were exposed and severed. An oxygenated solution was then pumped though the vasculature with a Buchler peristaltic pump, thereby replacing the blood. The entire dorsal surface of the CNS was subsequently exposed, and the spinal cord was removed. In addition, all cranial nerves except the optic nerve were sectioned to assure that no painful stimuli were relayed to the CNS. The preparation was then embedded in $1 \%$ agarose gel to stabilize the perfused brain. The perfusion solution was a HEPES-buffered frog Ringer's supplemented with glucose $(10 \mathrm{mM})$ and heparin. The pumping rate was typically held at $0.05 \mathrm{ml} /$ min, although a faster rate was often used during the first half-hour of perfusion to ensure that the blood was adequately flushed out. Good electrophysiological recordings could be obtained from perfused animals for up to 3 days when kept at $15^{\circ} \mathrm{C}$. The electrophysiological records of visually evoked RGC activity in the tectum from animals that were continuously perfused were not distinguishable from recordings of animals prepared in the standard manner (first method).

Recording electrodes for all experiments were tungsten in glass, which are known to pick up activity from both tectal cells and RGC terminal arborizations in the tectum (Grusser and Grusser-Cornehls, 1976). For optic nerve stimulation, bipolar stimulating electrodes were fabricated from two resin-coated tungsten microelectrodes (Frederick Haer \& Co., Brunswick, ME, No. 25-05-3) glued together and plated with gold. Amplifier cutoff frequency settings were $300 \mathrm{~Hz}$ and $30 \mathrm{kHz}$ for axon spikes and $10 \mathrm{~Hz}$ and $3 \mathrm{kHz}$ for field potential recordings. Electrical stimuli of 0.1 to $1.0 \mathrm{msec}$ duration and 1 to 10 $\mathrm{V}$ intensity were applied at a rate of $1.5 / \mathrm{sec}$.

\section{Results}

Tectal projection of RGCs in central retina. In $R$. pipiens, small injections into the optic pathway retrogradely label age-related groups of RGCs and anterogradely label the terminal arbors of these same cells in the optic tectum (Constantine-Paton et al., 1983; Reh et al., 1983). Furthermore, the optic pathway shows a high degree of chronological order; the axons of ganglion cells born at any particular stage assume a position throughout the tract that is characteristic of that stage and constant between animals. Consequently, small pellets of HRP can be placed in the tract so as to reproducibly label a given subset of RGCs, such as those only in central retina adjacent to the $\mathrm{ONH}$. Figure 1 illustrates the results obtained with this procedure for a T\&K XII tadpole that received a single HRP pellet insertion in the central part of the diencephalic optic tract. In Figure $1 a$, the flat mounted retina of this animal clearly shows a small central annulus of HRP-filled RGCs. Similarly, in the cut end of the optic nerve of this animal, a small central annulus of labeled fibers is present. In the whole mounted brain of this tadpole (Fig. 1c) a central ring of terminal arbors is filled with the HRP reaction product. In Figures $2 b$ and 3 , similar HRP injections have labeled ganglion cell terminals in T\&K XVIII and XXV animals, respectively. The T\&K XVIII animal (Fig. 2b) shows a pattern of label that is not annular, but is instead a single puff of terminal arbors. Flat mounts of the retinas of animals with this type of tectal label confirm that these terminals arise from a small disc of RGCs immediately dorsal to the ONH. In Rana, as well as other poikilothermic vertebrates, the first ganglion cells that become postmitotic consist of a small group just dorsal to the $\mathrm{ONH}$, whereas subsequent addition of RGCs occurs as annuli at the ciliary margin (Straznicky and Gaze, 1971; Grant and Rubin, 1980; Reh and Constantine-Paton, 1983). Therefore, such small central puffs of terminal label represent the exact projection position of the RGCs adjacent to the $\mathrm{ONH}$.

This method of labeling a small set of age-related ganglion cells and their terminals allowed us to determine the tectal position that cells at the $\mathrm{ONH}$ project to during larval development. The results using this method were the same as those obtained using the alternative procedure (see "Materials and Methods") in which the entire projection of the retina is labeled except for that region containing the terminals of cells lying adjacent to the ONH (Fig. $2 a$ ).

From an examination of the $\mathrm{ONH}$ position in Figures 1 to 3 it is clear that the central RGC terminals arborize at progressively more caudal points as the tadpole develops. In the T\&K XII animal the central retinal projection is in the rostral tectum (Fig. 1c). At T\&K XVIII (Fig. 2) the projection of the cells at the ONH, although still in the rostral tectum, has shifted caudally. Finally, at T\&K $\mathrm{XXV}$, in the postmetamorphic frog, the $\mathrm{ONH}$ position is in the approximate center of the tectal lobe, midway along its rostrocaudal extent (Fig. 3).

To obtain a quantitative assay of the movement of ganglion cell arbors during development, the distance between the projection point of the cells at the $\mathrm{ONH}$ and the rostral tectal pole was measured as described under "Materials and Methods." The results of these measures are shown in Figure 4 for tadpoles at T\&K XII and XVIII and for postmetamorphic frogs (T\&K XXV). Whereas the length of the entire tectum enlarges along the rostrocaudal axis by only $259 \mu \mathrm{m}$ on the average, the position of the arbors of ganglion cells at the $\mathrm{ONH}$ shifts caudally by almost $700 \mu \mathrm{m}$ during this same period. Therefore, the ratio of the $\mathrm{ONH}$ projection position to the total tectal length increases from $28 \%$ at T\&K XII to $51 \%$ at T\&K XXV. In other words, ganglion cells at the $\mathrm{ONH}$ in the postmetamorphic animal project very close to the rostrocaudal center of the tectum, whereas these same central retinal cells (Reh and ConstantinePaton, 1983) project to the rostral one-third of the tectum in the T\&K XII tadpole.

It should be noted that the measurements made on the whole mounted tecta were made after the brains were fixed and dehydrated. Such processing leads to a 40 to $50 \%$ shrinkage of the tissue (Constantine-Paton and Ferrarri-Eastman, 1981). Therefore, the actual movement of the terminals is likely to be almost twice that given in Figure 4. The animals from which these measurements were taken developed from T\&K XII to T\&K $\mathrm{XXV}$ in approximately 6 weeks, making the average rate of terminal movement approximately $33 \mu \mathrm{m} /$ day. The movement of RGC arbors through the tectal neuropil is 

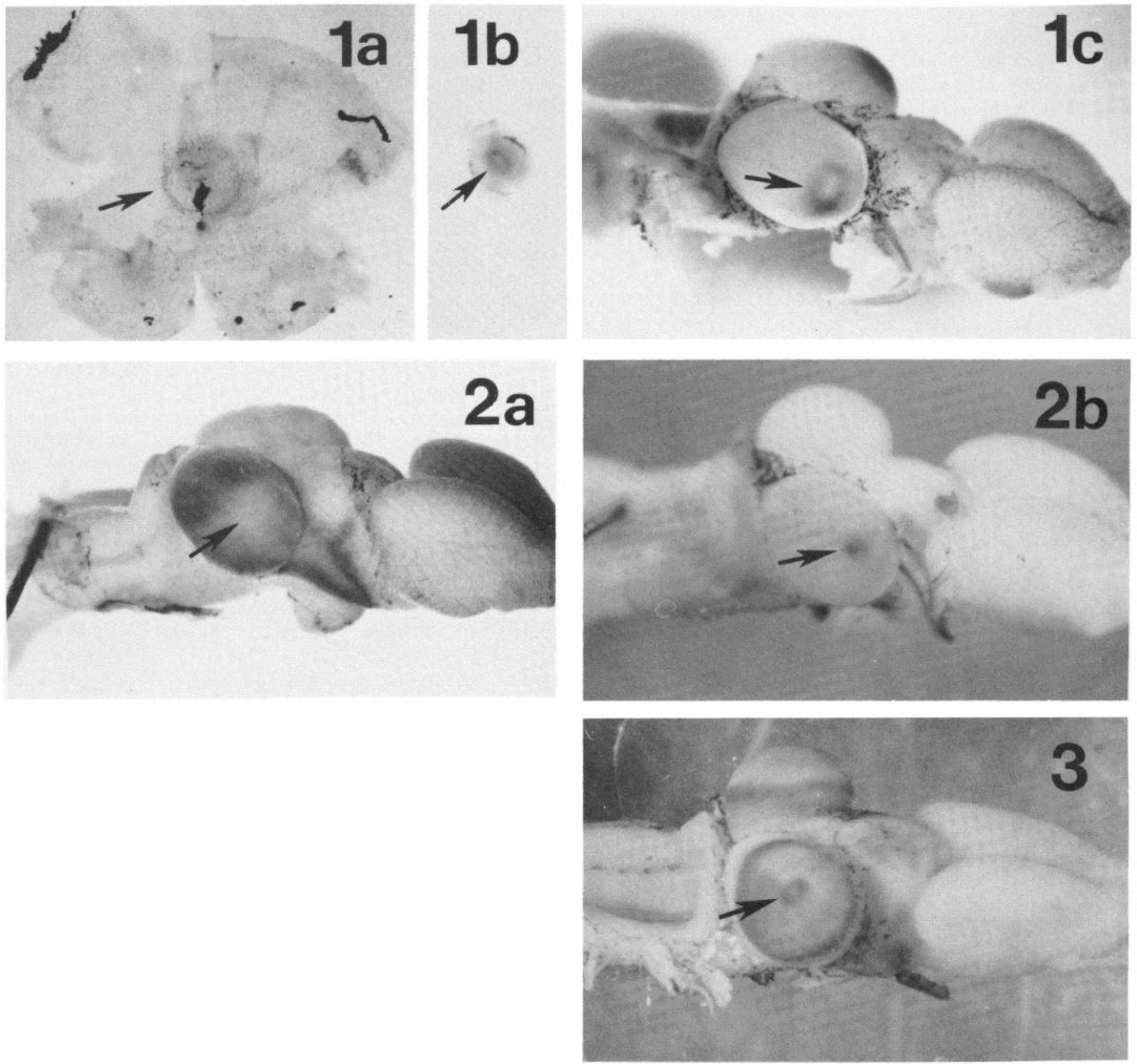

Figures 1 to 3. Figure 1, $a$ to $c$, shows photographs of the flat mounted retina $(a)$, cut surface of the optic nerve $(b)$, and whole mounted brain $(c)$ of a T\&K XII tadpole that received a small pellet insertion of HRP in the diencephalic optic tract, 1 day before sacrifice. The arrows in each photograph point to the labeled annulus of RGCs $(a)$, RGC axons in the nerve $(b)$, and RGC terminal arbors in the superficial tectal neuropil (c). Figure 2, $a$ and $b$, shows the whole mounted brains of two T\&K XVIII tadpoles. For the brain shown in Figure $2 a$, the entire retina except that immediately surrounding the ONH was removed 1 day before sacrifice, and the severed axons were filled with HRP. Thus only the terminals from the RGCs at the ONH remain unfilled (arrow). In Figure $2 b$, the animal received a small HRP injection in the diencephalic optic tract that selectively labeled only the most centrally located RGCs and their terminal arborizations in the tectum (arrow). Figure 3 is a photograph of a whole mounted brain from a postmetamorphic frog-1 week after complete tail regression-in which a small injection of HRP into the optic chiasm labeled two terminal annuli in the tectum and the corresponding ganglion cell bodies in the retina (not shown). The arrow points to the small central terminal annulus that marks the projection of RGCs located adjacent to the ONH. The brains shown in Figures 1 and 2 are at the same magnification $(\times 10)$ whereas the brain shown in Figure 3 is at a slightly lower magnification. The retina is magnified 12 times and the nerve 40 times.

thus a much slower process than axon regeneration in the optic nerve and tract (200 to $500 \mu \mathrm{m} /$ day; Grafstein and McQuarrie, 1978). This slower rate of growth is likely to be due to the fact that the RGC arbors must grow through a complex neuropil during their rostral-tocaudal movement.

It is clear from the preceding analysis that the arborizations of RGCs at the $\mathrm{ONH}$ are found at a progressively 


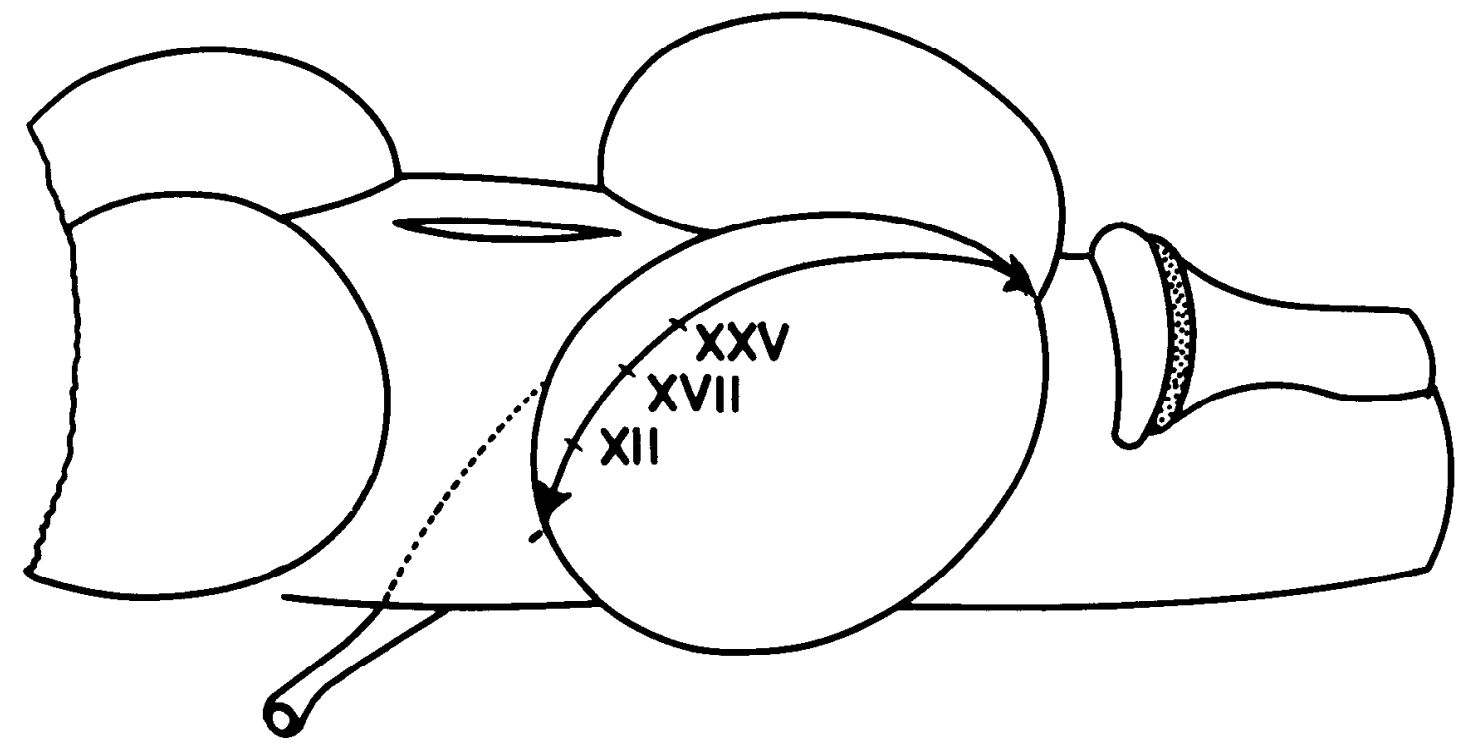

\section{T\&K Total tectal length $\mathrm{ONH}$ projection $\mathrm{ONH} /$ length $(\%)$}

\section{$X I I(n=6)$}

\section{$X V I I(n=6)$}

\section{$X X V(n=8)$}

$2657 \pm 227 \mu$

$2881 \pm 370 \mu$

$2916 \pm 173 \mu$
$778 \pm 170 \mu$

$1138 \pm 94 \mu$

$1471 \pm 245 \mu$
$28 \%$

$40 \%$

$51 \%$

Figure 4. Diagram of the tectal surface showing the approximate position to which cells at the ONH project their axons at three stages of development. Measurements were made on fixed, dehydrated material as described under "Materials and Methods."

more caudal point on the tectal surface as a tadpole matures to a postmetamorphic frog. However, to determine whether these terminals were shifting relative to the tectal cells, a small subset of tectal cells was permanently labeled with $\left[{ }^{3} \mathrm{H}\right]$ thymidine and the site of the $\mathrm{ONH}$ was charted relative to these stable, identified tectal markers. $\left[{ }^{3} \mathrm{H}\right]$ Thymidine injections permanently label all cells undergoing their final mitotic divisions at the time of the injection. In larval $R$. pipiens (Currie and Cowan, 1974) and Xenopus (Straznicky and Gaze, 1972) the dividing cells are restricted to a small proliferative zone along the caudal and medial tectal borders. Since tectal cells are produced at these borders only, the optic tectum elongates in a rostral-to-caudal fashion, with the oldest tectal cells at the rostral pole and the youngest tectal cells in the caudomedial tectum. Therefore, a $\left[{ }^{3} \mathrm{H}\right]$ thymidine injection at any larval stage results in a band of labeled tectal cells extending from rostromedial to caudolateral tectum, when the animals are fixed at a later stage.

Figure 5 shows the frontal sections through the tecta of animals that received $\left[{ }^{3} \mathrm{H}\right]$ thymidine injections at T\&K IV and in which the ONH projection site was determined at T\&K XII and XXV, respectively. The position of the $\mathrm{ONH}$ projection, marked with a small piece of hair (see "Materials and Methods"), can be seen in these sections. Also, the $\left[{ }^{3} \mathrm{H}\right]$ thymidine-labeled cells are visible as a discrete group, extending through all tectal cell layers in a well defined region of the tectum. In Figure 6, computer reconstructions of sections through the tecta of two such doubly labeled animals show the overall pattern of cell labeling and the position of the $\mathrm{ONH}$ projection site (marked by an $X$ ). These reconstructions show that at T\&K XII the most central RGCs project to tectal cells that were generated prior to $T \& K$ $\mathrm{IV}$, whereas at $\mathrm{T} \& \mathrm{~K} X X V$ these same ganglion cells now send their arbors to tectal cells generated after T\&K IV. Since the extent of the dendritic arborization of the vast majority of tectal cells is less than $50 \mu \mathrm{m}$ (Szekely and Lazar, 1976), RGCs must change the particular tectal cells to which they project during larval development.

Morphology of shifting terminal arbors. Since the reti- 

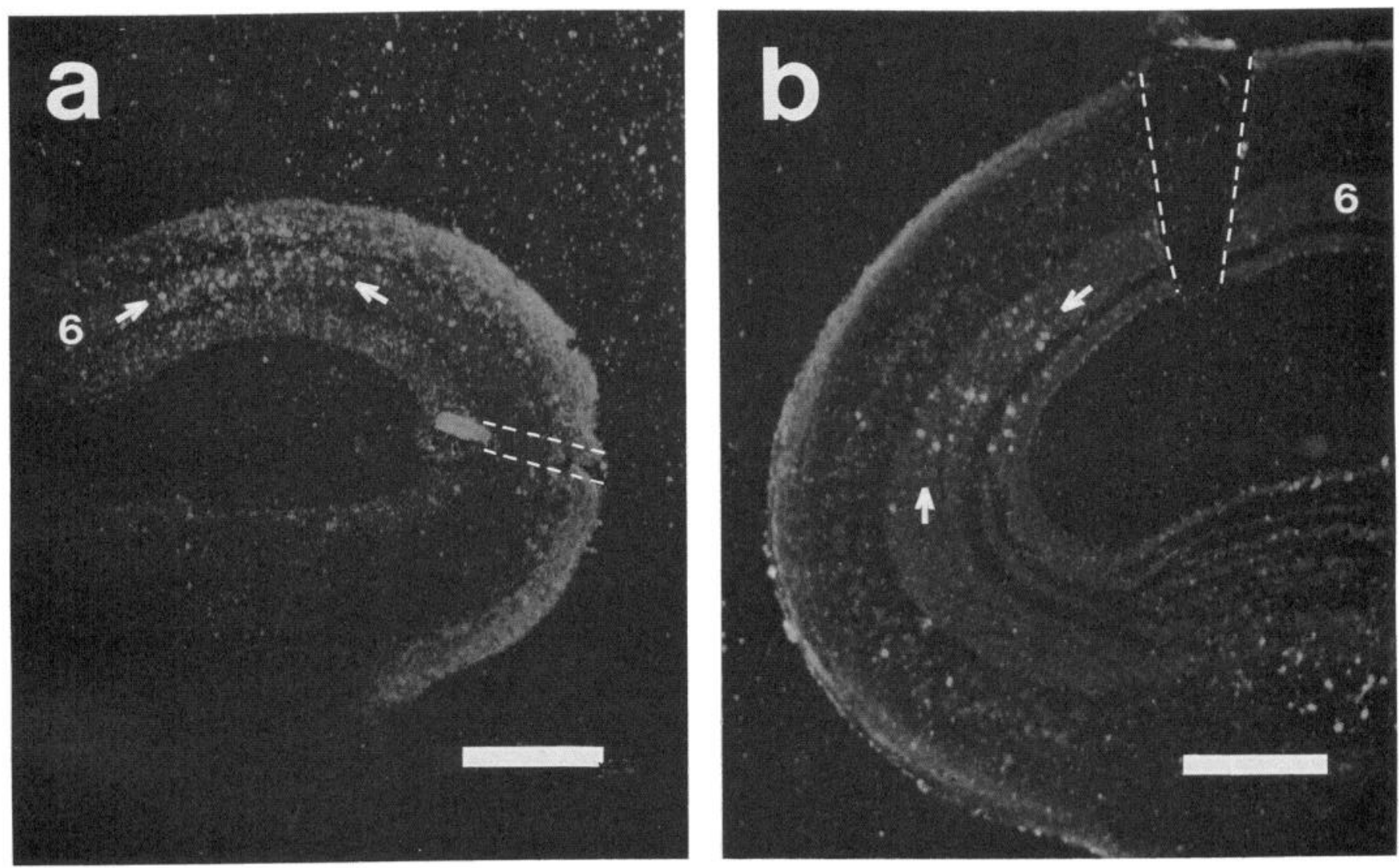

Figure 5. Darkfield photomicrographs of sections through the optic tecta of a T\&K XII tadpole $(a)$ and a postmetamorphic frog $(b) .\left[{ }^{3} \mathrm{H}\right]$ Thymidine-labeled tectal cell nuclei appear as bright spots (arrows), while the position of the fiber that identifies the ONH projection point is marked with dashed lines. Scale bar $=200 \mu \mathrm{m}$; tectal layer 6 is marked in both micrographs. Notice that the region of heaviest labeling of tectal cells is medial to the ONH at T\&K XII, whereas it is lateral to this point in the postmetamorphic frog.

nal projection is moving across the tectal surface continually during larval development, we looked for further evidence of this shift in the morphology of the terminal arborizations of the ganglion cells. In several animals (11), in which terminal annuli were labeled with HRP, the tecta were flat mounted and cleared. With this procedure the RGC axons and terminal arbors of labeled cells could be visualized and individual fibers could be followed throughout their trajectory. In this report the entire retinal process, including the parent axon and the secondary and tertiary branches, will be referred to as the RGC terminal arbor.

Figure 7 is a composite of camera lucida tracings of three RGC arbors from T\&K XII staged tadpoles. These fibers, all found in central tectum, represent the range of terminal arbors present at this and other larval stages. The process shown in Figure 7c was among the largest that we encountered, while Figure $7 a$ shows one of the smaller terminal arbors present at this stage. However, the majority of RGC terminal arbors in central tectum of larval animals have a morphology much like that shown in Figure $7 b$. Despite this substantial variation in the size and overall branching pattern of the RGC arborizations in the larval animals, certain common features serve to distinguish them from RGC terminals in the same region of postmetamorphic animals. First, the larval RGC processes have a pronounced rostrocaudal orientation in the trajectory of their secondary and tertiary branches. Although in postmetamorphic frogs the orientation of the parent axon is in a rostrocaudal direction for central terminal arbors, the secondary and tertiary branches have no such orientation, but rather arborize more densely at a more restricted locus along the rostrocaudal axis. (Constantine-Paton et al., 1983). Second, the RGC arbors in larval animals do not have a restricted locus of dense arborization that is characteristic of postmetamorphic terminals; instead, they are typically spread out over a greater tectal area, without a profusion of fine branches at any one position. Third, in the larval tecta, one often observes flattened, growth cone-like structures at the distal tips of the RGC processes (arrows in Fig. 7, $a$ to $c$ ). Higher magnification micrographs of three of these processes, along with accompanying camera lucida tracings, are shown in Figure 8. These structures often have both lamellipodia (Fig. 8, $a$ and $c$ ) as well as fine filopodial extensions (Fig. 8, $a$ and $b$ ) characteristic of growth cones observed both in vitro and in vivo (Ramon y Cajal, 1904; Harrison, 1910).

These differences in the morphology of RGC terminal arbors between larval and postmetamorphic animals are consistent with the idea that this projection is undergoing a rapid rostrocaudal shift in tadpoles. The presence 
TECTAL CELLS LABELED AT T\& $K$ IV

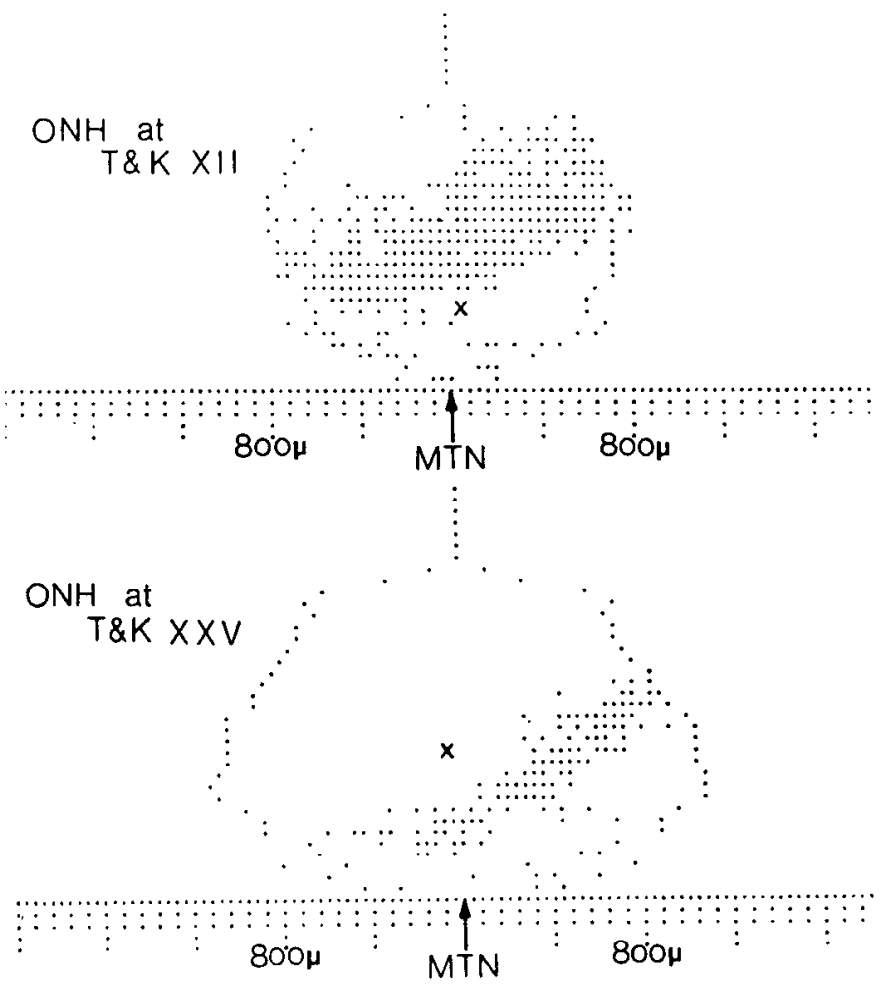

Figure 6. Computer reconstructions of the labeled tectal cells in a T\&K XII larva and a postmetamorphic frog that had each received a single injection of $\left[{ }^{3} \mathrm{H}\right]$ thymidine at T\&K IV. In all cases, labeled cells appear as a band of dots extending from the rostromedial tectum to the caudolateral tectum. Also charted for the same animals is the position in the tectum to which the cells at the ONH project at the stage the animal was fixed (marked with an $X$ ). Note that the ONH position at T\&K XII is rostral to tectal cells generated at $T \& K I V$, whereas at $T \& K$ $\mathrm{XXV}$ the $\mathrm{ONH}$ position is caudal to cells generated at T\&K IV. Compare with Figure 5 to relate the position of the $\mathrm{ONH}$ to the labeled cells that appear in the same coronal section.

of growth cones at the caudal tips of the terminals, along with the rostrocaudal orientation of the branches, suggests that the growth of these processes is primarily along this axis. In addition, the lack of a particular locus of more dense arborization, as is found in postmetamorphic terminals, is also consistent with the idea that the larval retinotectal system is highly labile.

Shifting RGC arbors make synaptic connections. To determine whether the ganglion cell arbors make functioning synaptic connections with tectal cells during their caudal shift, we examined the projection with electron microscopy and with electrophysiological methods.

Although the entire projection must be shifting during the larval stages examined, since we have specifically charted the movement of central RGCs, we looked for evidence of synaptic connections primarily in that region of tectum to which these ganglion cells projected at the stages examined. The labeled processes could be easily identified, as the DAB reaction product densely filled the cytoplasm and was only excluded from membrane bound organelles, such as mitochondria and synaptic vesicles (Fig. 9). Although this obscured the morphology to some extent, the relevant ultrastructural characteristics of axons and synaptic contacts could still be ascertained.

In all cases, HRP-filled axons, both myelinated and unmyelinated, were abundant throughout the superficial tectal neuropil (layer 9), but were sparse in the deeper tectal layers (below layer 8), and were absent below layer 6 . As in the postmetamorphic animal, there was a tendency for unmyelinated axons to lie more superficially in the neuropil than did myelinated fibers; however, a few labeled myelinated processes were present near the tectal surface.

Presynaptic terminals, labeled with the DAB reaction product, were present throughout the superficial neuropil. These labeled terminals were quite similar to those identified as RGC terminals by the degeneration technique in the mature postmetamorphic Rana tectum (Szekely and Lazar, 1976). These profiles (designated type 1, Szekely and Lazar, 1976) range from 0.5 to $2 \mu \mathrm{m}$ in diameter, contain numerous round synaptic vesicles, and possess only a few mitochondria. As is also typical of the type 1 terminal in the adult (Szekely and Lazar, 1976), the labeled processes in tadpoles often contact small, irregularly shaped dendritic profiles in asymmetric synapses with only a slight postsynaptic membrane thickening. Also, as is observed in the adult, the vesicles in type 1 terminals are at times clustered near the site of contact (Fig. 9c), whereas in other cases, they may fill the entire process.

Some differences were observed between the mature and larval neuropil. The RGC type 1 terminals of mature frogs often form glomeruli, containing six to eight axon terminals and three to six dendritic processes, surrounded by glial processes. These structures were never present in the central tectum of tadpoles. In addition, a large amount of extracellular space was characteristic of this tissue, a feature that is typical of immature amphibian CNS (Norlander and Singer, 1978; Gaze et al., 1979). Very rarely, an axosomatic contact was made by a labeled process. The contact shown in Figure $9 f$ is between an RGC process and a layer 8 tectal neuron. This paucity of axosomatic synapses does not appear to be unique to the immature tectum, since a similar lack of such contacts is also present in the mature postmetamorphic frog (Szekely and Lazar, 1976).

Another feature of the larval RGC processes that has not been observed in the postmetamorphic animal is the presence of large vesiculated structures filled with $\mathrm{DAB}$ reaction product (Fig. 9, $c$ and $d$ ). The large vesicles contained in these profiles closely resemble the growth cone vesicles described in several ultrastructural studies of developing CNS using similar fixation procedures (Hendrikson and Vaughn, 1974; Vaughn and Sims, 1978). In addition, these putative growth cones are occasionally observed to be in continuity with synaptic profiles (Fig. $9 d)$.

The electrophysiology of the optic tectum was studied using standard recording techniques and tungsten-inglass microelectrodes. These microelectrodes are known to record action potentials from both presynaptic terminal arbors and postsynaptic tectal cells (Grusser and Grusser-Cornehls, 1976). Recordings of afferents were made in the superficial neuropil of tadpoles at several 

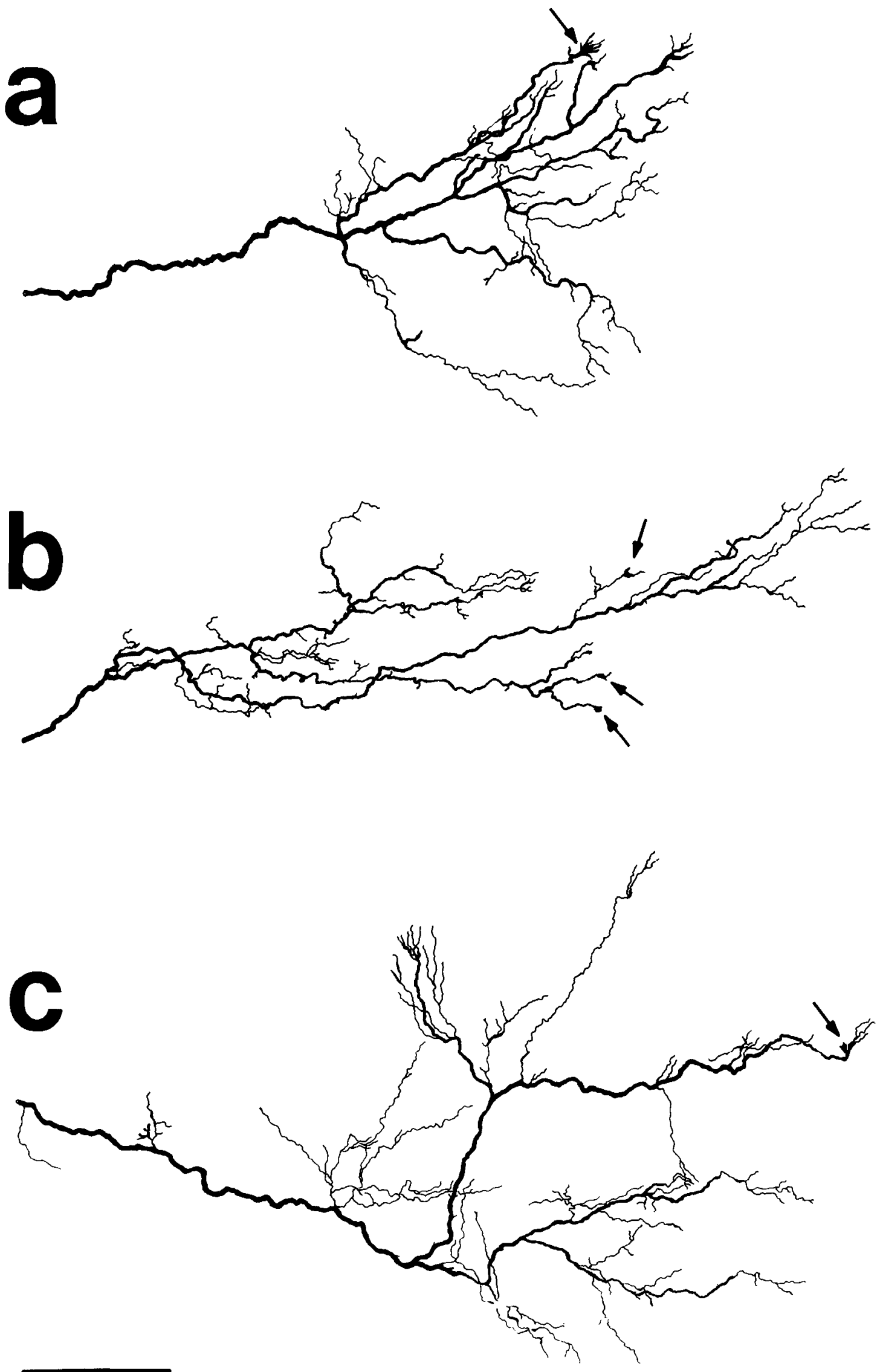

Figure 7. Three RGC terminal arborizations in the central tectum of T\&K XII tadpoles. These terminals, drawn from anterngrade HRP fills, represent the extremes of the branching patterns observed at this stage. The terminal shown in $b$ is of the morphology most commonly observed. Arrows point to flattened distentions often observed at the distal ends of these arbors. Scale bar $=50 \mu \mathrm{m}$. These drawings are oriented such that rostral is to the left and caudal is to the right. 

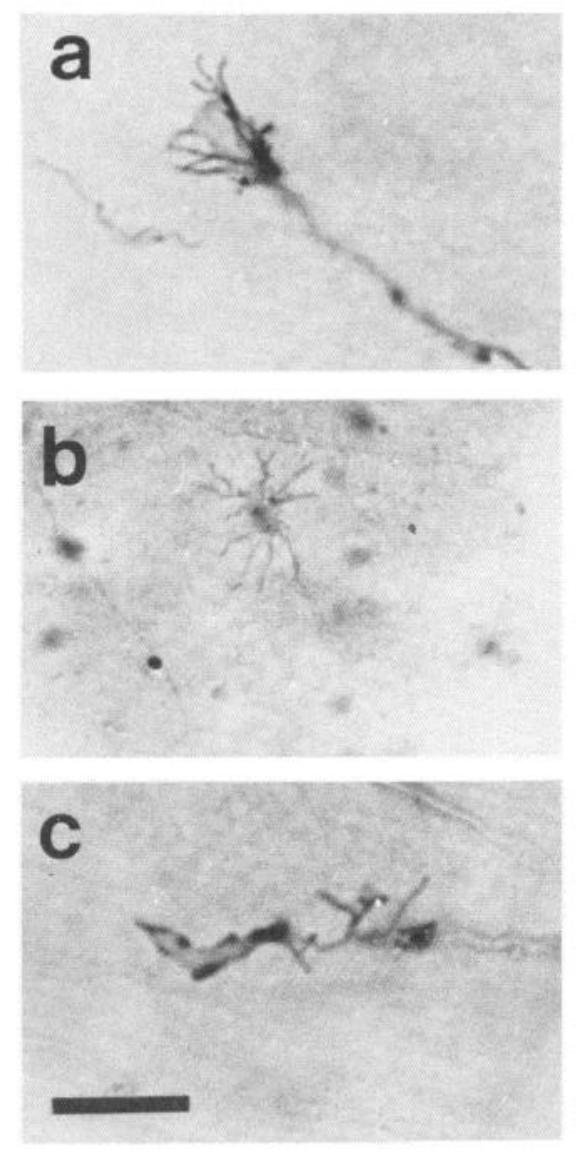

Figure 8. Photomicrographs and accompanying camera lucida drawings of growth cone-like structures at the tips of HRP-filled RGC terminal arborizations. These were taken from a T\&K XII tadpole. In all cases, caudal is to the left, rostral is to the right. Scale bar $=5 \mu \mathrm{m}$.
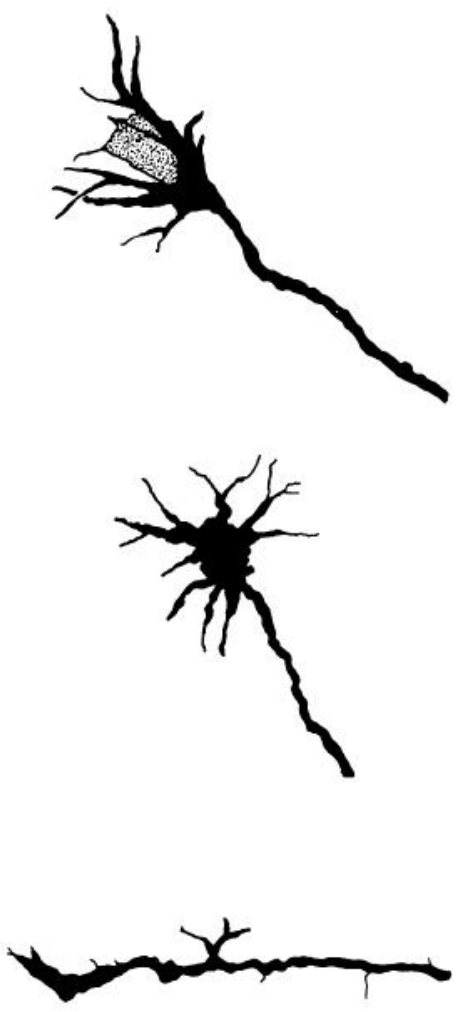

stages. All classes of RGC fibers normally found in adult Rana could be recorded in central tectum as early as $\mathrm{T} \& \mathrm{~K} \mathrm{X}$, and no difference in response properties could be detected between animals that were continuously perfused with oxgenated media (see "Materials and Methods") and those prepared for recording by conventional methods (Fig. 10).

Evidence for functional synaptic connections between ganglion cells and tectal cells in larval animals was obtained using field potential analysis in perfused CNS preparations. Tadpoles of various stages or young postmetamorphic frogs were perfused and the responses to visual field stimulation and direct electrical stimulation of the optic nerve were recorded from the central region of the optic tectum. At each stage examined these recording positions were chosen so as to fall near the locus identified anatomically as the projection zone of central retina. Stimulation of the optic nerve produces a complex field potential in the tectal neuropil which reflects both pre- and postsynaptic transmembrane potentials. It was possible to separate the presynaptic potentials from the postsynaptic potential in the larval animals by several manipulations. In Figure 11 the results of one such manipulation-adding $5 \mathrm{~mm}$ cobalt to the perfusion solution-are shown. The field potential is shown prior to the addition of the cobalt (Fig. 11A), 5 min after the cobalt has reached the preparation (Fig. 11b), and 20 min after the cobalt solution was washed out (Fig. 11c). As can be seen in the figure, the large, late, negativegoing components of the potential are selectively and reversibly blocked by the cobalt ions, whereas the earlier components are not affected. The same results were also obtained when the calcium ions in the media were replaced with magnesium, although the negative potential took considerably longer to completely disappear, presumably because the $\mathrm{Ca}^{2+}$ was slow to wash out of the tissue; since these two treatments, low $\mathrm{Ca}^{2+}$ or the addition of $\mathrm{Co}^{2+}$, are known to block synaptic transmission, it is likely that this large potential is postsynaptic to the RGC axons. RGC terminals must be making functional synaptic contacts despite the fact that, during this same period, these same terminals are shifting their arborizations caudally in the tectal neuropil. These shifts are made relative to the tectal target cells and encompass distances much larger than the extent of tectal dendrites. Therefore, the postsynaptic partners of retinal axons must continually shift during the development of the retinotectal pathway in Rana.

\section{Discussion}

Shifting retinotectal connections. To reconcile the disparate spatial patterns of growth of the retina and the optic tectum with the presence of an ordered map of connections between the two structures in Xenopus tad- 

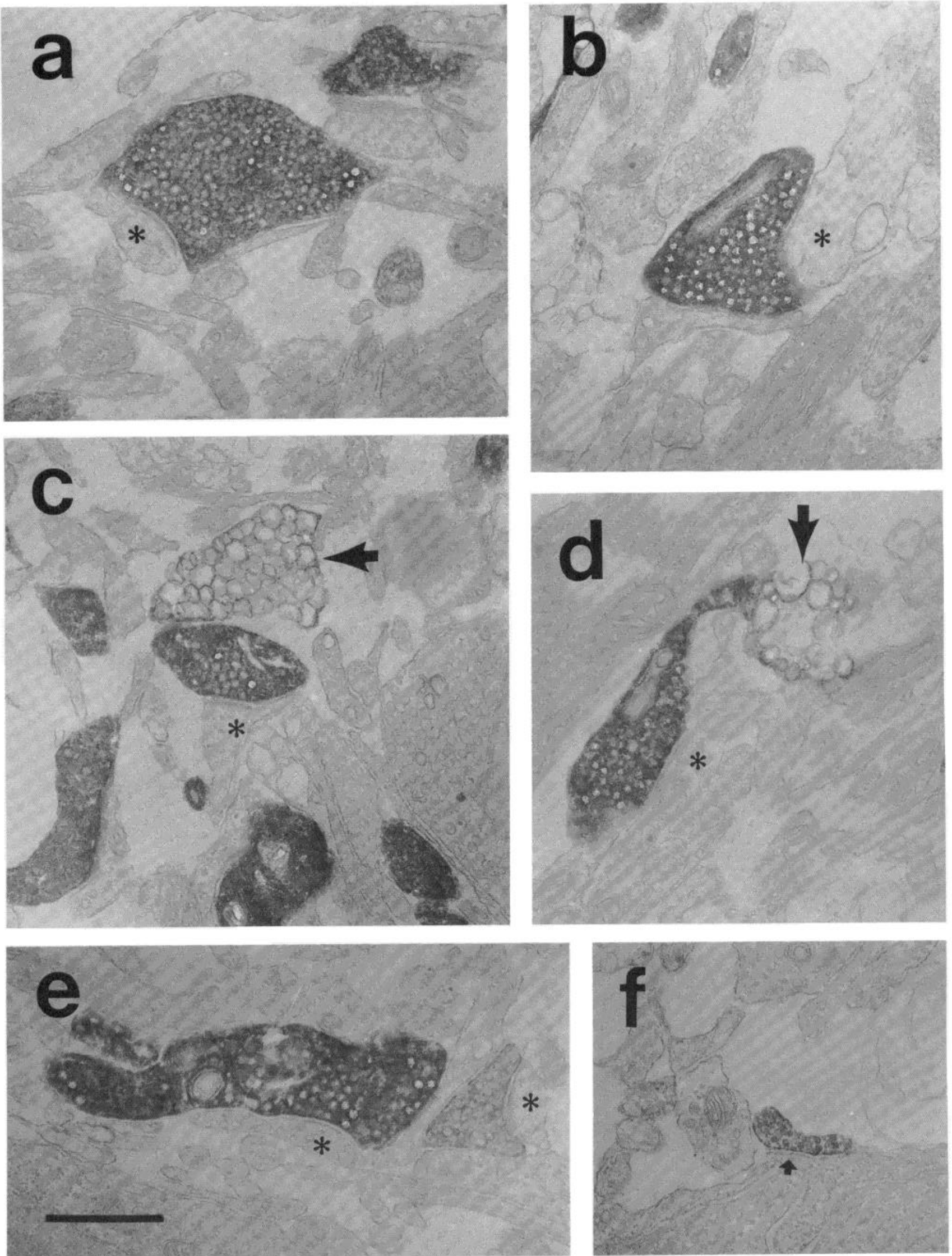

Figure 9. Electron micrographs of HRP-filled terminal boutons of RGC arbors showing synaptic connections with small dendritic profiles (marked by asterisks in $a$ to $e$ ) and with a layer 8 tectal neuron (marked by an arrow in $f$ ). In $c$ and $d$, HRPfilled structures with large growth cone-like vesicles are marked by arrows. Scale bar $=0.5 \mu \mathrm{m}$. 
10

11
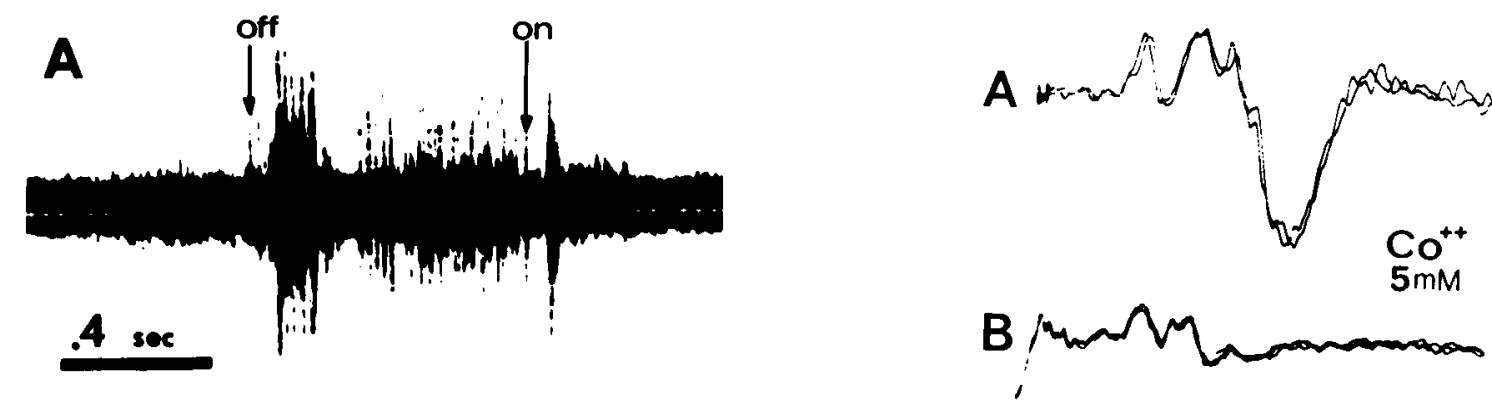

B
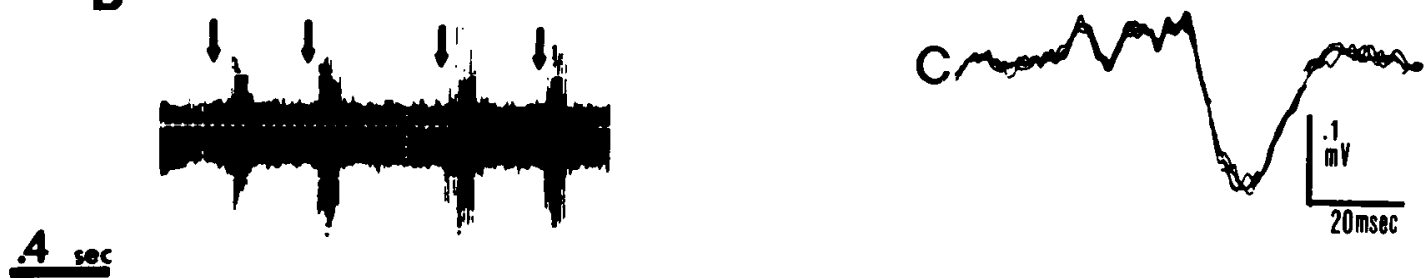

Figure 10. Extracellular records of visually evoked activity from the central tectum of a T\&K XII tadpole. In $A$ the responses of dimming detectors and changing contrast detectors are elicited when the overall retinal illumination is suddenly decreased (off) and then increased approximately $1 \mathrm{sec}$ later (on). In $B$ a small black disc was repeatedly presented (arrows) to the receptive field of this unit. The responses to these stimuli are identical to those obtained when the animal was prepared with conventional physiological techniques.

Figure 11. This figure shows field potentials recorded in the central tectum (at approximately the position to which the RGCs at the ONH project) of a single stage T\&K XII tadpole while the contralateral optic nerve was electrically stimulated at $0.5 /$ sec with shocks of $4 \mathrm{~V}$ of $0.1 \mathrm{msec}$ duration. In $A$, the potential is shown prior to the addition of $5 \mathrm{mM} \mathrm{CoCl}_{2}$ to the medium, $B$ shows the potential recorded during perfusion of the $\mathrm{CoCl}_{2}$ medium, and $C$ was recorded 20 min after the $\mathrm{CoCl}_{2}$ medium was flushed out of the preparation. For each record, the depth of the recording electrode was held constant at $100 \mu \mathrm{m}$ below the pial surface. Each record represents several superimposed traces, and positive is upward. Note that the early positive potentials remain during the cobalt treatment while the larger, longer-latency negative potential is reversibly inhibited when cobalt is added to the medium.

poles, Gaze et al. (1974) proposed that RGC arbors continually change their termination sites, and thus the particular tectal cells they contact, during larval development. Since this theory was advanced, several attempts have been made to test for the possibility of "shifting retinotectal connections" in Xenopus, but the results have been equivocal.

The initial correlative evidence for shifting connections has been challenged on a number of grounds. First, Jacobson (1978) argued that, although retinal growth does not match that of the optic tectum, it may match the pattern of growth of the primary projection sites of the retinal ganglion cells as a whole. New retinal cells without a tectal match could conceivably project to other targets, such as the diencephalic visual centers. Second, further study of retinal histogenesis demonstrated marked asymmetries in the concentric addition of RGCs and in their density along the dorsoventral axis of the retina (Beach and Jacobson, 1979). The fact that such asymmetric growth occurs in the retina brings it more into line with the pattern of growth in the tectum. Third, the initial demonstration of a visuotopic map of retinotectal afferents in tadpoles did not take into account possible developmental changes in the dioptric apparatus of the eye, nor was any evidence provided for the claim that RGC axons were making synaptic contact with tectal cells. Although subsequent studies by Gaze and his collaborators (Chung et al., 1974; Gaze et al., 1979) addressed these criticisms, a direct demonstration of shifting connections was lacking.

Previous anatomical investigations, devised in an attempt to detect a shift in the tectal projection sites of RGC terminals, were inconclusive. Double labeling of both the complete retinotectal projection with $\left[{ }^{3} \mathrm{H}\right]$ proline and the tectal cells with $\left[{ }^{3} \mathrm{H}\right]$ thymidine was employed by three laboratories in an attempt to test the shifting connection hypothesis (Scott and Lazar, 1976; Jacobson, 1977; Gaze et al., 1979). However, this technique has serious difficulties, in that transneuronal transport of the $\left[{ }^{3} \mathrm{H}\right]$ proline is quite likely over the long survival periods required to test for a shift in the projection (typically several weeks). Thus, it is not surprising that, whereas Scott and Lazar (1976) and Gaze et al. (1979) have interpreted their results as being consistent with shifting connections, Jacobson (1977) failed to find any evidence of a shift in the projection using the same technique over the same stages of development. Other methods used to determine the tectal projection site of a particular region of the retina in progressively older tadpoles have examined the tectum for degenerating axon terminals following retinal lesions (Longley, 1978; Gaze et al., 1979). However, RGC axons often survive 
for long periods of time following separation from the soma (Lazar, 1980; Matsumoto and Scalia, 1981). Moreover, many developing systems show a substantial amount of natural cell death and degeneration during development (Cowan, 1973; Cunningham, 1981). Thus, although the results obtained by degeneration methods were consistent with the hypothesis of shifting connections, other interpretations of these data were possible.

More recently, Fraser (1983) has employed a fiber optic light pipe technique to map the tectal position to which the $\mathrm{ONH}$ projects in Xenopus tadpoles during metamorphic climax. This technique revealed an average "shift" of only $150 \mu \mathrm{m}$ during the stages in which the visuotopic map undergoes its most dramatic changes. Since this distance is spanned by a single RGC arborization in Xenopus tadpoles (Lazar, 1973), the terminals in this species may only need to shift slightly, whereas the large changes in the visuotopic map that occur during this period (Gaze et al., 1974) are probably due to the differential ventral retinal growth (Jacobson, 1977; Beach and Jacobson, 1979; Gaze et al., 1979; Tay et al., 1982). By contrast, this same light pipe mapping technique shows a much greater shift in Rana (S. E. Fraser, personal communication).

The present study of the development of the visual system of $R$. pipiens does not suffer from the difficulties of the earlier work on Xenopus. A prior study has demonstrated that the central RGCs immediately adjacent to the $\mathrm{ONH}$ are generated in the early Rana embryo and remain in this same position for as long as 1 year past metamorphosis (Reh and Constantine-Paton, 1983). We have now shown that this identified group of ganglion cells, at the $\mathrm{ONH}$, changes the position of its arborizations in the tectum with respect to a stable group of $\left[{ }^{3} \mathrm{H}\right]$ thymidine-labeled tectal cells. Throughout this same period, the electron microscopic demonstration of presynaptic terminals filled after HRP application to the optic nerve shows that RGC arbors make synaptic connections with tectal cells in tadpoles; the electrophysiological results indicate that these synapses are functional.

Implications for retinotectal map formation. Our results indicate that there is a striking and continual rearrangement of synaptic connections during larval development of $R$. pipiens; however, the relative order of the afferents is maintained throughout this process. The cellular interactions that establish the precisely ordered pattern of retinotectal connections, as well as the consistent alignment and overall extent of the map, must operate in the context of this extremely dynamic synaptic readjustment. Shifting connections thus argue against theories of retinotectal map formation that postulate the existence of fixed cytochemical labels that specify connections by allowing synapse formation only between retinal and tectal cells with corresponding labels (Sperry, 1963; Meyer and Sperry, 1976). During normal development, such cell-specific "labels" would have to change continuously as the projection shifts its position caudally. Therefore, fixed cytochemical labels cannot be the sole determinant of positional specification of RGC terminal loci. This conclusion is also supported by numerous experiments that demonstrate considerable plasticity in the tectal connections of regenerating RGC terminals following surgical removal of retinal or tectal halves in adult frogs (Udin, 1977) and goldfish (Yoon, 1972; Meyer, 1978; Schmidt et al., 1978) and by studies of the tectal projections of experimentally produced combinations or duplications of particular embryonic retinal regions (Gaze et al., 1963; see Gaze, 1970, for review). However, none of these studies completely rule out a role for region-specific differences in adhesiveness between retinal and tectal cells in the development of the retinotectal map. On the contrary, several investigators have reported that rotation or translocation of tectal grafts results in a rotation or translocation in the corresponding region of the retinotectal map (Yoon, 1972; Jacobson and Levine, 1975). In addition, experiments in both frogs and goldfish in which the tectal lobes are dually innervated by both normal eyes (Meyer, 1979; Law and Constantine-Paton, 1980) or by embryologically added supernumerary eye (Constantine-Paton and Law, 1978; Straznicky et al., 1980) demonstrate that partial projections from the additional eye can only compete with the normal eye (and thus terminate) in the retinotopically appropriate tectal region.

No single mechanism has been adequate to explain all of the experimental results obtained in this system: those that demonstrate its plasticity as well as those that stress its specificity. Consequently, several recent reviews have proposed that multiple mechanisms may be operating during development and regeneration to ensure appropriate topography of the retinotectal projection (Willshaw and von der Marlsburg, 1979; Whitelaw and Cowan, 1981; Constantine-Paton, 1982; Meyer, 1982). In addition, Law and Constantine-Paton (1981) have argued that the formation of eye-specific RGC terminal stripes in dually innerated tecta requires the interaction between two separate developmental mechanisms. In their scheme, graded, regionally varying affinities of RGCs for their appropriate tectal area are responsible for the overall alignment of the normal map. At the same time a second mechanisms serves to preserve the proximity relationships of RGC bodies by ordering the RGC terminals in the tectum. This second mechanism stabilizes neighboring RGC terminals in the tectum only if they arise from ganglion cells that are neighbors in the retina. This process, therefore, "fine tunes" the normal map during development and causes eye-specific segregation when two different retinas attempt to innervate the same tectal cells.

This two-stage model can account for the continual shifting of a highly ordered map in the following way. The first ganglion cell axons to reach the tectum arborize in their appropriate tectal quadrant. The initial orientation and the gross topography of the projection could be established at this time by positionally varying affinities between retinal and tectal cells. This aspect of the mapping process may well involve the cell surface components that have been shown in vitro to mediate selective adhesion between RGCs of a given retinal region and cells or membrane fractions from the corresponding locus on the tectum (Marchase et al., 1975; Halfler et al., 1981; Bonhoeffer and Huff, 1982). As new RGCs are added, their growth cones reach the tectal borders and begin to grow into the tectal neuropil. In the caudal- 
medial tectum, where new tectal neurons are being produced, the nasal RGC terminals are unimpeded in their interactions with the differentiating postsynaptic cells. However, in the rostral tectum, newly arriving terminals from temporal retina must displace already present arbors from more centrally located temporal RGCs. Within the context of the proposed two-stage mapping model, there are several ways in which this displacement could occur. First, the positionally graded affinities of retinal axons for tectal cells could cause movement of the projection if, at any point in development, the terminals of the most temporally located ganglion cells have the highest affinity for the most rostral tectal cells, and therefore displace all other retinal axons from these cells. A second possible mechanism is that newly generated, uninnervated tectal cells at the caudomedial border might signal to nearby RGC terminals to spread in a caudal direction. Finally, a third possibility is that the second phase of the mapping process, the mechanism that preserves retinal neighbor relationships, might provide the motive force for terminal displacement. The terminals of newly generated temporal retinal cells will attempt to terminate at the rostral tectal border near the arbors of the temporal RGCs generated previously. This would increase the competition for space in rostral tectum and effectively push the entire projection caudalward. Regardless of the actual combination of the interactions involved, the proposed proximity-preserving mechanism could act throughout development to maintain a high degree of relative order among the terminals during the pronounced shifting that occurs.

Although the available evidence from experimental manipulations in the retinotectal system, as well as the present study of the normal development, is consistent with the hypothesis that two separate mechanisms operate during map formation, the nature of these mechanisms remains the subject of considerable debate. Overall matching of retinal and tectal cells from corresponding regions via selective adhesive interactions may well underly the gradients of affinity proposed in the present study, but it is unlikely that the low level of specificity that has been demonstrated to date in vitro can fully account for the high level of order present in this system.

The proposed second stage of map formation would eliminate the need for a high degree of precision in cell surface matching since it would increase point-to-point order in the projection through competitive interactions among the afferent fibers. Considerable evidence suggests that neural activity is involved in such competitive interactions during neural development. Both visually evoked (see Hubel et al., 1977, for review) and spontaneous neural activity (Stryker, 1981; Archer et al., 1982) have now been implicated in the interactions between inputs which lead to a refinement of connectivity in the mammalian retinogeniculocortical system. Moreover, a number of studies have noted changes in the retinotectal system of non-mammalian vertebrates following perturbations of RGC activity (Chung et al., 1973; Keating and Feldman, 1975; Udin and Keating, 1981; Meyer, 1982; Constantine-Paton and Reh, 1983; Schmidt and Edwards, 1983). The activity-dependent competitive interactions which refine the retinotopy and response prop- erties might well be the same as those involved in shifting the map across the tectum of developing tadpoles; however, this issue has not yet been specifically addressed.

Retinotectal map formation in other vertebrates. The patterns of growth of the retina and the tectum are similar in the vertebrates that have been studied; thus one might expect the developmental mechanisms to cross species lines. Retinal cell proliferation and differentiation during development in teleost fish (Hollyfield, 1972), chick (Rager, 1980), rat (Braekevelt and Hollenberg, 1970), and cat (Rapaport and Stone, 1982) proceed with a central-to-peripheral gradient, similar to that observed for $R$. pipiens. The optic tectum differs in these species, in that tectal cells proliferate and differentiate in a ventrolateral to dorsomedial sequence in chick (LaVail and Cowan, 1971; but see also Rager and Von Oeynhausen, 1979), goldfish (Meyer, 1978), and rodents (Altman and Bayer, 1981).

These observations suggest that some type of synaptic rearrangement occurs during the development of the retinotectal system in most vertebrates. Other observations also support this hypothesis. In the chick, there is good evidence that the retinotectal projection is initially imprecise and becomes "fine-tuned" in a subsequent stage (McLoon, 1982). Also, Easter and Stuermer (1982) have argued that movement of retinotectal terminals is necessary to explain the axon trajectories observed in the mature goldfish.

In summary, we have provided direct evidence that RGC arbors continually change the tectal cells they synapse with during the larval development of Rana pipiens. Such moving, but highly ordered connections can best be explained by a two-stage mechanism for map formation, in which graded, selective adhesions between cells in appropriate regions of retina and tectum provide the overall gross retinotopy of the projection, while competitive interactions between RGC terminals are responsible for refining and maintaining the precision of the system. It is likely that these synaptic rearrangements occur during the development of the retinotectal system in many vertebrates since the species that have been studied show similar disparities in their patterns of retinal and tectal growth.

\section{References}

Altman, J., and S. A. Bayer (1981) Time of origin of neurons of the rat superior colliculus in relation to other components of the visual and visuomotor pathways. Exp. Brain Res. 42: 424-434.

Archer, S. M., M. W. Dubin, and L. A. Stark (1982) Abnormal development of kitten retino-geniculate connectivity in the absence of action potentials. Science 217: 743-745.

Beach, D. H., and M. Jacobson (1979) Patterns of cell proliferation in the retina of the clawed frog during development. J. Comp. Neurol. 183: 603-614.

Bonhoeffer, F., and J. Huff (1982) In vitro experiments on axon guidance demonstrating an anterior-posterior gradient on the tectum. EMBO J. 1: 42-45.

Braekevelt, C. R., and M. J. Hollenberg (1970) The development of the retina of the albino rat. Am. J. Anat. 127: 281302.

Chung, S. H., R. M. Gaze, and R. V. Stirling (1973) Abnormal visual function in Xenopus following stroboscopic illumina- 
tion. Nature New Biol. 246: 186-188.

Chung, S. H., M. J. Keating, and T. V. P. Bliss (1974) Functional synaptic relations during the development of the retinotectal projection in amphibians. Proc. R. Soc. Lond. (Biol.) 187: 449-459.

Constantine-Paton, M. (1982) The retinotectal hookup: The process of neural mapping. In Developmental Order: Its Origin and Regulation, S. Subtelny, ed., pp. 317-349, Alan R. Liss, Inc., New York.

Constantine-Paton, M., and P. Ferrarri-Eastman (1981) Topographic and morphometric effects of bilateral embryonic eye removal in the optic tectum and nucleus isthmus of the leopard frog. J. Comp. Neurol. 196: 645-662.

Constantine-Paton, M., and M. I. Law (1978) Eye-specific termination bands in tecta of three-eyed frogs. Science 202: $639-641$.

Constantine-Paton, M., and T. Reh (1983) Eye-specific stripes in the tectal lobes of three-eyed frogs are dependent on neural activity. Soc. Neurosci. Abstr. 9: 760.

Constantine-Paton, M., E. Pitts, and T. A. Reh (1983) The relationship between retinal axon ingrowth, terminal morphology, and terminal patterning in the optic tectum of the frog. J. Comp. Neurol., in press.

Cowan, W. M. (1973) Neuronal death as a regulative mechanism in the control of cell number in the nervous system. In Development and Aging in the Nervous System, M. Rockstein, ed., pp. 19-41, Academic Press, Inc., New York.

Cunningham, T. (1982) Naturally occurring neuron death and its regulation by developing neural pathways. Int. Rev. Cytol. 74: 163-186.

Currie, J. R. (1975) Some observations on the development of the visual system of the frog. Chap. II. Thesis, Washington University, St. Louis.

Currie, J., and W. M. Cowan (1974) Some observations on the early development of the optic tectum in the frog (Rana pipiens) with special reference to the early eye removal on mitotic activity in the larval tectum. J. Comp. Neurol. 156 . 123-142.

Easter, S. S., and C. A. O. Stuermer (1982) Evidence for naturally occurring movements of retinotectal terminals in goldfish. Soc. Neurosci. Abstr. 8: 745 .

Easter, S. S., Jr., A. C. Rusoff, and P. E. Kish (1981) The growth and organization of the optic nerve and tract in juvenile and adult goldfish. J. Neurosci. 1: 793-811.

Fraser, S. E. (1983) Fiber optic mapping of the Xenopus visual system shift in the retinotectal projection during development. Dev. Biol. 95: 505-511.

Fujisawa, H., K. Watanabe, N. Tani, and Y. Ibata (1981) Retinotopic analysis of fiber pathways in amphibians. I. The adult newt Cynops pyrhogaster. Brain Res. 206: 9-20.

Gaze, R. M. (1970) The Formation of Nerve Connections, Academic Press, Inc., New York.

Gaze, R. M., M. Jacobson, and G. Szekely (1963) The retinotectal projection in Xenopus with compound eyes. J. Physiol. (Lond.) 165: 484-499.

Gaze, R. M., M. J. Keating, and S. H. Chung (1974) The evolution of the retinotectal map during development in Xenopus. Proc. R. Soc. Lond. (Biol.) 185: 301-330.

Gaze, R. M., M. J. Keating, A. Ostberg, and S. H. Chung (1979) The relationship between retinal and tectal growth in larval Xenopus. Implications for the development of the retinotectal projection. J. Embryol. Exp. Morphol. 53: 103-143.

Grafstein, B., and I. G. McQuarrie (1978) Role of the nerve cell body in axonal regeneration. In Neuronal Plasticity, C. W. Cotman, ed., Raven Press, New York.

Grant, P., and E. Rubin (1980) Ontogeny of the retina and optic nerve in Xenopus laevis. II. Ontogeny of the optic fiber pattern in the retina. J. Comp. Neurol. 189: 593-613.
Grusser, O. J., and U. Grusser-Cornehls (1976) Neurophysiology of the anuran visual system. In Frog Neurobiology, R. Llinas and W. Precht, eds., Springer-Verlag, Berlin.

Halfler, W., M. Claviez, and U. Schwarz (1981) Preferential adhesion of tectal membranes to anterior embryonic chick retinal neurites. Nature 292: 67-70.

Harrison, R. G. (1910) The outgrowth of the nerve fiber as a mode of protoplasmic movement. J. Exp. Zool. 9: 787-846.

Hendrikson, C. K., and J. E. Vaughn (1974) Fine structural relationships between neurites and radial glial processes in developing mouse spinal cord. J. Neurocytol. 3: 659-675.

Hollyfield, J. G. (1968) Differential addition of cells to the retina in Rana pipiens tadpoles. Dev. Biol. 18: 163-179.

Hollyfield, J. G. (1972) Histogenesis of the retina in the killifish, Fundulus heteroclitus. J. Comp. Neurol. 144: 373-380.

Hubel, D. H., T. N. Wiesel, and S. LeVay (1977) Plasticity of ocular columns in monkey striate cortex. Philos. Trans. R. Soc. Lond. (Biol.) 278: 377-409.

Innocenti, G. M. (1981) Growth and reshaping of axons in the establishment of visual callosal connections. Science 212: 824-827.

Jacobson, M. (1977) Mapping the developing retinotectal projection in frog tadpoles by a double label autoradiographic technique. Brain Res. 127: 55-67.

Jacobson, M. (1978) Developmental Neurobiology, Holt, Rinehart \& Winston, Inc., New York.

Jacobson, M., and R. L. Levine (1975) Plasticity in the adult frog brain: Filling in the visual scotoma of the excision or translocation of parts of the optic tectum. Brain Res. 88 : 339-345.

Keating, M. J., and J. D. Feldman (1975) Visual deprivation and intertectal neuronal connections in Xenopus laevis. Proc. R. Soc. Lond. (Biol.) 191: 467-474.

LaVail, J. H., and W. M. Cowan (1971) The development of the chick optic tectum. II. Autoradiographic studies. Brain Res. 28: 421-441.

Law, M. I., and M. Constantine-Paton (1980) Right and left eye bands in frogs with unilateral tectal ablations. Proc. Natl. Acad. Sci. U. S. A. 77: 2314-2318.

Law, M. I., and M. Constantine-Paton (1981) Anatomy and physiology of experimentally produced striped tecta. J. Neurosci. 1: 741-759.

Lazar, G. (1973) The development of the optic tectum in Xenopus laevis: A Golgi study. J. Anat. 116: 347-355.

Lazar, G. (1980) Long-term persistence, after eye-removal, of unmyelinated fibers in the frog visual pathway. Brain Res. 199: 219-224.

Longley, A. (1978) Anatomical mapping of retino-tectal connections in developing and metamorphosed Xenopus: Evidence for changing connections. J. Embryol. Exp. Morphol. 45: $249-270$.

Lund, R. D. (1978) Development and Plasticity of the Brain, Oxford University Press, London.

Marchase, R. B., A. J. Barbera, and S. Roth (1975) A molecular approach to retinotectal specificity. Ciba Found. Symp. 29: 315-327.

Matsumoto, D. E., and F. Scalia (1981) Long-term survival of centrally projecting axons in the optic nervae of the frog following destruction of the retina. J. Comp. Neurol. 202: 135-155.

McLoon, S. C. (1982) Alterations in precision of the crossed retinotectal projection during chick development. Science 215: $1418-1420$

Meyer, R. L. (1978) Evidence from thymidine labeling for continuing growth of retina and tectum in juvenile goldfish. Exp. Neurol. 59: 99-111.

Meyer, R. L. (1979) "Extra" optic fibers exclude normal fibers from tectal regions in goldfish. J. Comp. Neurol. 183: 883- 
902.

Meyer, R. L. (1982) Tetrodotoxin blocks in the formation of ocular dominance columns in goldfish. Science 218: 589-591.

Meyer, R. L. (1982) Ordering of retinotectal connections: A multivariate operational analysis. Curr. Top. Dev. Biol. 17: 101-145.

Meyer, R. L., and R. W. Sperry (1976) Retinotectal specificity: Chemoaffinity theory. In: Studies on the Development of Behavior and the Nervous System. Vol. 3: Neural and Behavioral Specificity, G. Gottlieb, ed., pp. 111-149, Academic Press, Inc., New York.

Norlander, R. E., and M. Singer (1978) The role of ependyma in regeneration of the spinal cord in urodele amphibian tail. J. Comp. Neurol. 180: 349-374.

Rager, G. (1980) Development of the Retinotectal Projection in the Chicken, Springer-Verlag, Berlin.

Rager, G., and B. Von Oeynhauser (1979) Ingrowth and ramification of retinal fibers in the developing optic tectum of the chick. Exp. Brain Res. 35: 213-227.

Rakic, P. (1976) Prenatal development of the visual system in rhesus monkey. Philos. Trans. R. Soc. Lond. (Biol.) 278: 245260.

Ramon y Cajal, S. (1904) Histologie du Systeme Nerveux de l'Homme et des Vertebres, Vol. 1, pp. 597-98, Consejo Superior de Investigaciones Cientificas, Madrid.

Rapaport, D. H., and J. Stone (1982) The site of commencement of maturation in mammalian retina: Observations in the cat. Dev. Brain Res. 5: 273-279.

Reh, T., and M. Constantine-Paton (1983) Qualitative and quantitative measures of plasticity during normal development of retinotectal connections in the frog, Rana pipiens. Dev. Brain Res. 10: 187-200.

Reh, T. A., E. Pitts, and M. Constantine-Paton (1983) The organization of the fibers in the optic nerve of normal and tectumless Rana pipiens. J. Comp. Neurol. 218: 282-296.

Schmidt, J. T., and D. L. Edwards (1983) Activity sharpens the map during the regeneration of the retinotectal projection in goldfish. Brain Res. 269: 29-39.

Schmidt, J. T., D. M. Cicerone, and S. S. Easter (1978) Expansion of the half retinal projection to the tectum in goldfish: An electrophysiological and anatomical study. J. Comp. Neurol. 177: 257-278.

Scott, T. M., and G. Lazar (1976) An investigation into the hypothesis of shifting neuronal relationships during development. J. Anat. 121: 485-496.

Sperry, R. W. (1963) Chemoaffinity in the orderly growth of nerve fiber patterns and connections. Proc. Natl. Acad. Sci. U. S. A. 50: 703-710.

Springer, A. D. (1980) Aberrant regeneration in goldfish after crushing one optic nerve. Brain Res. 199: 214-218.

Straznicky, C., and R. M. Gaze (1971) The growth of the retina in Xenopus laevis: An autoradiographic study. J. Embryol. Exp. Morphol. 26: 67-79.

Straznicky, C., and R. M. Gaze (1972) The development of the tectum in Xenopus laevis: An autoradiographic study. J. Embryol. Exp. Morphol. 28: 87-115.

Straznicky, C., D. Tay, and J. Hiscock (1980) Segregation of optic fiber projections into eye-specific bands in dually innervated tecta in Xenopus. Neurosci. Lett. 19: 131-136.

Stryker, M. P. (1981) Late segregation of geniculate afferents to the cat's visual cortex after recovery from binocular impulse blockade. Soc. Neurosci. Abstr. 7: 842.

Szekeley, G., and G. Lazar (1976) Cellular and synaptic architecture of the optic tectum. In Frog Neurobiology, R. I linas and W. Precht, eds., Springer-Verlag, Berlin.

Tay, D., J. Hiscock, and C. Straznicky (1982) Temporal-nasal asymmetry in the accretion of retinal ganglion cells in late larval and postmetamorphic Xenopus. Anat. Embryol. 164: 75-83.

Taylor, A. C., and J. J. Kollros (1946) Stages in the development of Rana pipiens larvae. Anat. Rec. 94: 7-23.

Tsukahara, N. (1981) Synaptic plasticity in the mammalian central nervous system. Annu. Rev. Neurosci. 4: 351-380.

Udin, S. (1977) Rearrangements of the retinotectal projection in Rana pipiens after unilateral caudal half-tectum ablation. J. Comp. Neurol. 173: 561-582.

Udin, S., and M. J. Keating (1981) Plasticity in a central nervous system pathway in Xenopus. Anatomical changes in the isthmotectal projection after larval eye rotations. J. Comp. Neurol. 203: 575-594.

Vaughn, J. E., and T. J. Sims (1978) Axonal growth cones and developing axonal collaterals form synaptic junctions in embryonic mouse spinal cord. J. Neurocytol. 7: 337-363.

Whitelaw, V. A., and J. D. Cowan (1981) Specificity and plasticity of retinotectal connections: A computational model. J. Neurosci. 1: 1369-1387.

Willshaw, D. J., and C. von der Malsburg (1979) A marker induction mechanism for the establishment of ordered neural mapping: Its application to the retinotectal problem. Philos. Trans. R. Soc. Lond. (Biol.) 287: 203-243.

Yoon, M. G. (1972) Reversibility of the reorganization of retinotectal projection in goldfish. Exp. Neurol. 35: 565-577. 